\title{
Clinicopathological Significance of HER2/neu Expression in Gastric Carcinoma
}

\author{
Ashim Manta ${ }^{1 *}$ and Pranita Medhi ${ }^{2}$ \\ ${ }^{1}$ Department of Pathology, Basic science Building, Assam Medical College \& Hospital, Dibrugarh-786002, Assam, India \\ ${ }^{2}$ Department of Pathology, Jorhat Medical College, Jail Road, Jorhat-785001, Assam, India
}

\begin{abstract}
Background: Gastric cancer remains the most common cause of cancer related death worldwide. HER2/neu protein overexpression in gastric carcinoma was found to be an independent indicator of poor prognosis.

The present study was designed to evaluate the frequency of HER2/neu expression in gastric carcinoma, and also the relationship between HER2/neu expression with clinicopathological parameters.

Methods: Analysis of HER2/neu expression was done by immunohistochemistry in 41 specimens of Gastric carcinoma over a period of one year and was correlated with clinicopathological parameters. Samples with IHC score 2+ and 3+ were taken as HER2 positive.

Result: The study revealed $15(36.6 \%)$ cases of gastric carcinoma being positive for HER2/neu. Of the 41 cases, 5 were classified as score $3+(12.2 \%), 10$ were classified as score $2+(24.4 \%), 11$ were classified as score $1+(26.8 \%)$ and 15 were classified as score $0(36.6 \%)$. Peak incidence was found in the age group of 41-50 years. Significant correlation of HER2/neu expression was found with intestinal type $(\mathrm{p}$-value $=0.003)$ and also with moderately differentiated type (p-value $=0.018)$ of gastric adenocarcinoma. However, no significant correlation was found with the other clinicalpathological parameters like age, sex, site, lymph node status and staging.
\end{abstract}

Conclusion: HER-2/neu over-expression was significantly associated with intestinal type and moderately differentiated gastric carcinoma. HER2/neu status can be considered as an important prognostic factor in gastric carcinoma.

\section{Keywords: Gastric Carcinoma, HER2/neu, Immunohistochemistry, Clinicopathological.}

\section{Introduction}

Carcinoma stomach is the fourth most commonly diagnosed cancer in the world and is also the second most common cause of cancer-related deaths. ${ }^{1}$ Worldwide it accounts for $7.8 \%$ of cancers. ${ }^{2}$ In India, the annual incidence rate of gastric cancer is 10.6 per 100000 population. ${ }^{3}$ As per the data obtained from the National Cancer Registries, the rate of gastric cancer is more in North-eastern and Southern states of Indian subcontinent. However, in North-eastern registries the rates for gastric cancer are higher than that of rest of the country. ${ }^{4}$

In majority of the cases, patients present at an advanced stage, when the tumor is unresectable and systemic chemotherapy remains the main stay of treatment. The overall survivality of patients has improved using various chemotherapeutic combinations. However, new targeted therapeutic approaches are essential for better prognosis. Recently, HER2 has been validated as a molecular target for this disease. ${ }^{5}$

HER2/neu (c-erb-2) is an oncogene, encoding a transmembrane glycoprotein that has tyrosine kinase activity known as p185, which belongs to the family of epidermal growth factor receptors. ${ }^{6}$ Several biological functions such as cell proliferation, differentiation, motility, and apoptosis are regulated by HER-2. It was reported that over-expression of HER-2 is seen in many types of cancer like breast, lungs, salivary gland, ovary, colon, prostate and pancreas. ${ }^{7,8}$ HER-2 is over-expressed in $10 \%-38 \%$ of gastric cancer patients. ${ }^{9}$ However, the correlation between the expression of HER-2 protein and the prognosis of gastric cancer is still controversial. Different studies have shown varied levels of HER-2 expression in gastric carcinoma. ${ }^{10,11,12}$

Trastuzumab (Herceptin) is a fully humanized monoclonal antibody. Targeting the extracellular domain of the HER2 receptor, Trastuzumab prevents its activation. Currently it is being used for the treatment of HER2-positive breast cancer and has shown to improve survival in patients with HER-positive breast cancer. ${ }^{13}$ Researchers are now studying the antitumor activity of Trastuzumab in patients with HER2-positive gastric adenocarcinomas.

In the recently concluded Trastuzumab for Gastric cancer $(\text { ToGA })^{14}$ trial, it was shown that patients receiving trastuzumab treatment protocol had an improved overall survival over those not receiving this treatment. 
Various studies have been conducted across the globe to study the frequency of Her2/neu expression in gastric carcinoma, but very few published data are available on Indian population. Hence, the present study is being undertaken to assess the frequency of HER2/neu in gastric carcinoma patients and also to evaluate its association with the clinicopathological parameters.

\section{Materials and Methods}

The present study was conducted on the biopsy specimens of stomach received at a tertiary care hospital in Dibrugarh. It was a hospital based cross sectional study consisting of forty one samples of primary gastric adenocarcinoma (endoscopic/ excision biopsy specimens) collected over a duration of one year (June 2014 to May 2015). Detailed clinical data of the patients were obtained as per the patient's clinical data sheet.

Inclusion criteria: Histopathologically confirmed gastric carcinoma cases received either as endoscopic biopsy or post gastrectomy biopsy specimen.

\section{Exclusion criteria:}

1. Cases with extensive tumour necrosis without sufficient viable tumour cells.

2. Patients receiving prior chemotherapy.

3. Non-compliant patient or patient not willing to participate in the study.

Ethical clearance was taken from the Institutional ethical committee before commencement of the study.

Histopathology: Tissues were grossed in detail and then fixed in 10\% buffered formalin and subsequently tissues were processed according to standard protocol. 3-5 $\mu$ thick sections were stained with hematoxylin and eosin stain and were examined for the histopathological type and the grade of the tumor. Further sections were subjected to immunohistochemistry (IHC).

\section{Immunohistochemistry:}

IHC staining was done using HER2 (BioGenex, mouse Ig). Positive and negative cases of control group were taken during the staining procedure of IHC. Known case of HER2/neu positive $(3+)$ breast cancer tissue was used as positive control for HER2/neu immunostaining whereas normal gastric mucosal glands which were negative for HER2/neu, were taken as negative control

HER2/neu scoring for gastric cancer was done as proposed by Hoffman et $\mathrm{al}^{11}$ with scores as follows: 0 , no reactivity or membranous reactivity in $<10 \%$ of cells; $1+$, faint/barely perceptible membranous reactivity in $>10 \%$ of cells ( cells are reactive only in part of their membrane); $2+$, weak to moderate complete or basolateral membranous reactivity in
$>10 \%$ of tumour cells \& $3+$, moderate to strong complete or basolateral membranous reactivity in $>10 \%$ of tumour cells.

Cases with HER2 score of 0 and $1+$ were considered HER2 negative, while cases with HER2 score of 2+ and 3+ were considered HER2 positive. For cases with HER2 score of $2+$, FISH analysis is recommended, but we could not do it in our study due to economic constraints. Statistical evaluation was done to look into the expression profile among various subgroups of gastric carcinoma with chisquare test. A p-value of $<0.05$ was considered significant.

\section{Result}

Our study included 41 cases of gastric carcinoma (33 endoscopic biopsy and 8 surgical resection specimens). There were 28 male patients and 13 female patients with Male:Female ratio of 2.15:1. Age ranged from 21-80 years with a mean age of $51.4 \pm 10.14$ years. The most common site of gastric carcinoma was antrum (68.3\%) with 25 cases $(60.9 \%)$ showing an ulcerative growth. (Figure: 1) Majority of the cases of gastric adenocarcinomas were of intestinal type (60.9\%). (Figure: 2) Most of the tumours were of poorly differentiated type (51.2\%).Of the 41 cases, 13 cases $(31.7 \%)$ had lymph node metastasis and 12 cases $(29.3 \%)$ were in Stage IV. (Table:1)

Out of 41 cases, 15 cases (36.6\%) had HER2/neu score 0 , followed by 11 cases (26.8\%) with HER2/neu score 1+ (Figure: 5), 10 cases (24.4\%) with HER2/neu score $2+$ (Figure: 4$)$ and 5 cases (12.2\%) with HER2/neu score 3+ (Figure: 3).(Table:2) HER2 overexpression $(2+/ 3+$ immunostaining on IHC) was found in 15 cases $(36.6 \%)$ while HER 2 negative $(0 / 1+$ immunostaining on IHC) cases comprised 26 cases $(63.4 \%)$.

In our study, HER2/neu expression was more in the intestinal type 14 cases $(56 \%)$ followed by the diffuse type 1 case $(7.1 \%)$. HER2/neu status was found to be significantly associated with types of Gastric adenocarcinoma ( $p$ value $=0.003)$.(Graph:1) We found HER2/neu expression more in the moderately differentiated carcinoma 6 cases(75\%). A significant association was observed between HER2/neu status and degree of differentiation of gastric carcinoma ( $\mathrm{p}$ value $=0.018)$. (Graph:2)

\section{Discussion}

The present study was carried out to see the expression of HER2/neu in gastric carcinoma patients and correlate it with clinicopathological parameters. Our study revealed HER2/neu overexpression of $36.6 \%$ taking IHC score of $2+$ and $3+$ as HER2 positive. However, we found only $12.2 \%$ cases with $3+$ positivity. Hence, the actual HER2 positivity rate would be lower. 
Table 1: HER2/neu expression of gastric carcinoma with clinicopathological parameters.

\begin{tabular}{|c|c|c|c|c|}
\hline \multirow{2}{*}{\multicolumn{2}{|c|}{ Parameter }} & \multicolumn{2}{|c|}{ HER2/neu expression } & \multirow{2}{*}{ p-value } \\
\hline & & \multirow{2}{*}{$\begin{array}{c}\text { IHC score }(0 /+1) \\
12\end{array}$} & \multirow{2}{*}{$\begin{array}{c}\text { IHC score }(+2 /+3) \\
06\end{array}$} & \\
\hline \multirow{2}{*}{ Age } & $<50$ & & & \multirow{2}{*}{0.237} \\
\hline & $>50$ & 14 & 09 & \\
\hline \multirow{2}{*}{ Gender } & Male & 20 & 08 & \multirow{2}{*}{0.118} \\
\hline & Female & 06 & 07 & \\
\hline \multirow{4}{*}{ Tumour site } & Antrum & 18 & 10 & \multirow{4}{*}{0.916} \\
\hline & Body & 04 & 03 & \\
\hline & Cardia & 01 & 01 & \\
\hline & Fundus & 03 & 01 & \\
\hline \multirow{3}{*}{$\begin{array}{l}\text { Type of tumor } \\
\text { (Lauren's } \\
\text { classification) }\end{array}$} & Intestinal & 11 & 14 & \multirow{3}{*}{0.003} \\
\hline & Mixed & 02 & 0 & \\
\hline & Diffuse & 13 & 01 & \\
\hline \multirow{3}{*}{$\begin{array}{l}\text { Histological } \\
\text { differentiation }\end{array}$} & Well differentiated & 07 & 05 & \multirow{3}{*}{0.018} \\
\hline & $\begin{array}{l}\text { Moderately } \\
\text { differentiated }\end{array}$ & 02 & 06 & \\
\hline & Poorly differentiated & 17 & 04 & \\
\hline \multirow{2}{*}{$\begin{array}{l}\text { Lymph node } \\
\text { metastasis }\end{array}$} & Present & 08 & 05 & \multirow{2}{*}{0.865} \\
\hline & Absent & 18 & 10 & \\
\hline \multirow{2}{*}{ Stage } & I and II & 20 & 09 & \multirow{2}{*}{0.251} \\
\hline & III and IV & 06 & 06 & \\
\hline
\end{tabular}

Table2: HER2/neu scoring of Gastric adenocarcinoma

\begin{tabular}{|c|c|c|}
\hline Score & No. of case & Percentages \\
\hline 0 & 15 & 26.6 \\
\hline+1 & 11 & 24.4 \\
\hline+2 & 10 & 12.2 \\
\hline+3 & 5 & 100 \\
\hline
\end{tabular}

Table 3: HER2/neu status versus type of gastric carcinoma (lauren's classification) by various authors:

\begin{tabular}{|c|c|c|c|c|c|}
\hline \multirow{2}{*}{ Author } & \multirow{2}{*}{ Year } & \multicolumn{3}{|c|}{ HER2 status with Histological type } & \multirow{2}{*}{ p-value } \\
\hline & & Intestinal & Diffuse & Mixed & \\
\hline Rajagopal I et al. ${ }^{15}$ & 2015 & $32.7 \%$ & $0 \%$ & - & 0.054 \\
\hline Gordon MA et $\mathrm{al}^{16}$ & 2013 & $53 \%$ & $36 \%$ & $7 \%$ & $<0.001$ \\
\hline Tewari $\mathrm{M}$ et $\mathrm{al}^{17}$ & 2013 & $45 \%$ & $12 \%$ & - & 0.006 \\
\hline Movagharnejad $\mathrm{K}$ et $\mathrm{al}^{22}$ & 2013 & $12 \%$ & $6 \%$ & - & $>0.05$ \\
\hline Gomez-Martin C et al ${ }^{23}$ & 2012 & $11 \%$ & $4 \%$ & - & 0.064 \\
\hline Yan SY et al ${ }^{18}$ & 2011 & $22.1 \%$ & $5.4 \%$ & $4.5 \%$ & $<0.05$ \\
\hline Barros-Silva JD et al ${ }^{19}$ & 2009 & $81.6 \%$ & $7.9 \%$ & $10.5 \%$ & 0.007 \\
\hline Raziee HR et al ${ }^{20}$ & 2007 & $33 \%$ & $5 \%$ & $0 \%$ & 0.001 \\
\hline Tanner $\mathrm{M}$ et $\mathrm{al}^{21}$ & 2005 & $21.5 \%$ & $2.2 \%$ & $5.3 \%$ & 0.005 \\
\hline Present study & 2015 & $56 \%$ & $7.1 \%$ & $0 \%$ & 0.003 \\
\hline
\end{tabular}


Table 4: HER2/neu status versus degree of differentiation by various authors:

\begin{tabular}{|c|c|c|c|c|c|}
\hline \multirow[t]{2}{*}{ Author } & \multirow[t]{2}{*}{ Year } & \multicolumn{3}{|c|}{ HER2 status with Degree of differentiation } & \multirow[t]{2}{*}{ p-value } \\
\hline & & Well differentiated & Moderately differentiated & Poorly differentiated & \\
\hline Rajagopal I et al. ${ }^{15}$ & 2015 & $11.1 \%$ & $37.5 \%$ & $0 \%$ & 0.042 \\
\hline Shan L et al ${ }^{24}$ & 2013 & $16 \%$ & $20.1 \%$ & $6.1 \%$ & $<0.01$ \\
\hline Yan SY et al ${ }^{18}$ & 2011 & $16.7 \%$ & $11.4 \%$ & $16.9 \%$ & $>0.05$ \\
\hline Raziee HR et $a^{20}$ & 2007 & $41 \%$ & $11 \%$ & $7 \%$ & 0.001 \\
\hline Present study & 2015 & $41.7 \%$ & $75 \%$ & $19 \%$ & 0.018 \\
\hline
\end{tabular}

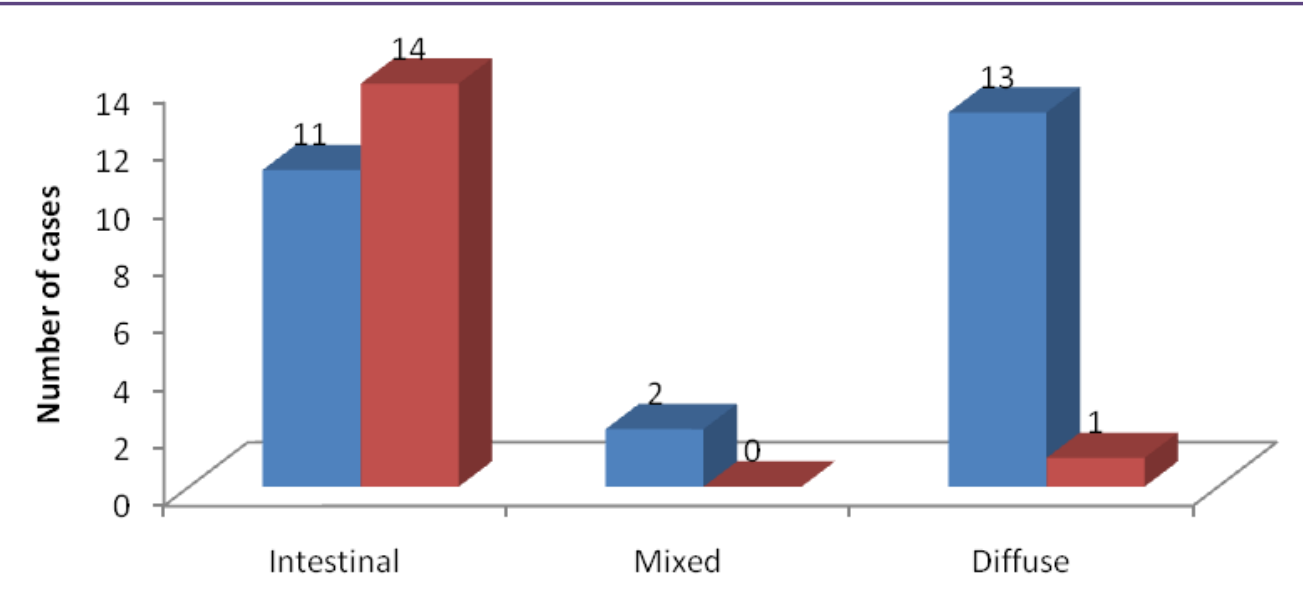

types of Gastric adenocarcinoma

- HER2/neu negative $(0 /+1) \quad$ HER2/neu positive $(+2 /+3)$

Graph 1: HER2/neu status versus types of Gastric adenocarcinoma (LAUREN'S Classification).

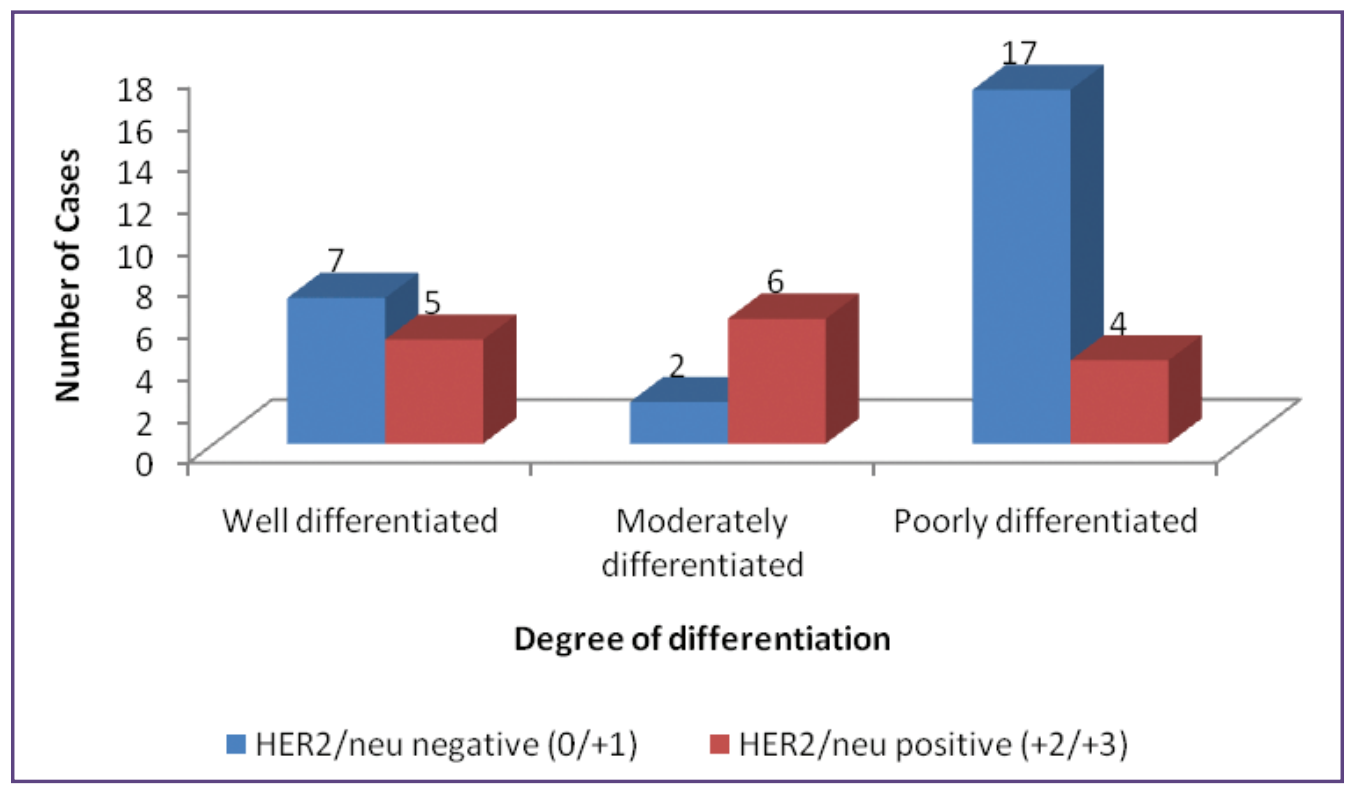

Graph 2: HER2/neu status versus Degree of differentiation of gastric adenocarcinoma. 


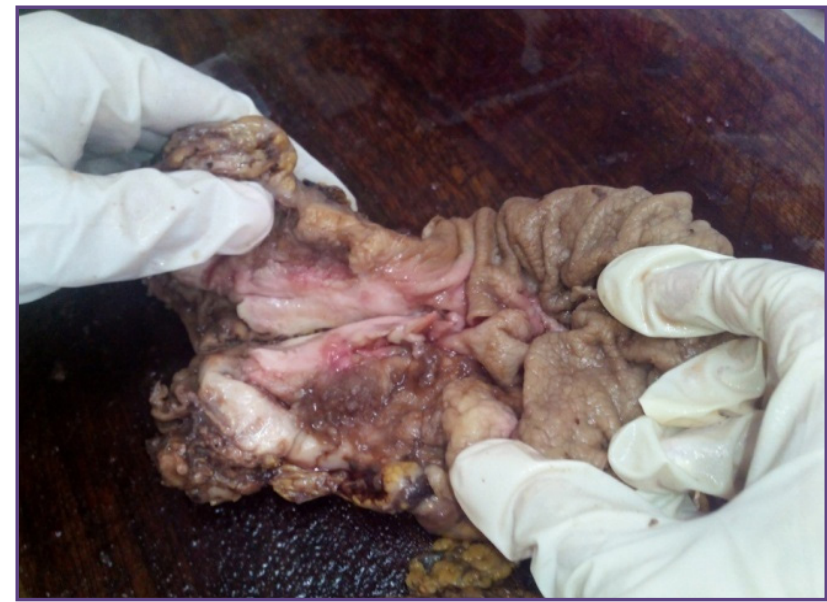

Fig.1: Gross Specimen of Stomach Showing an Ulcerative Growth.

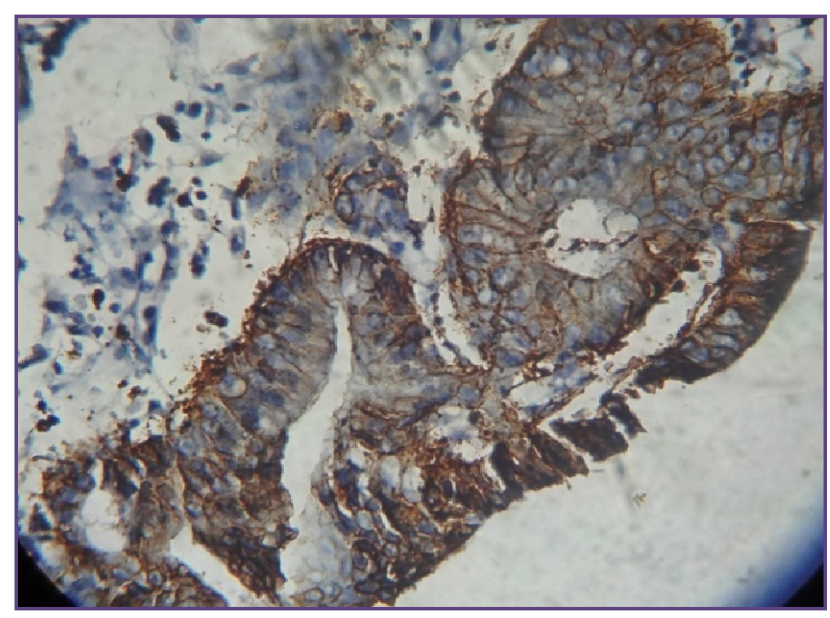

Fig. 3: Ihc Showing Complete Membrane Staining (Score $3+$ ).

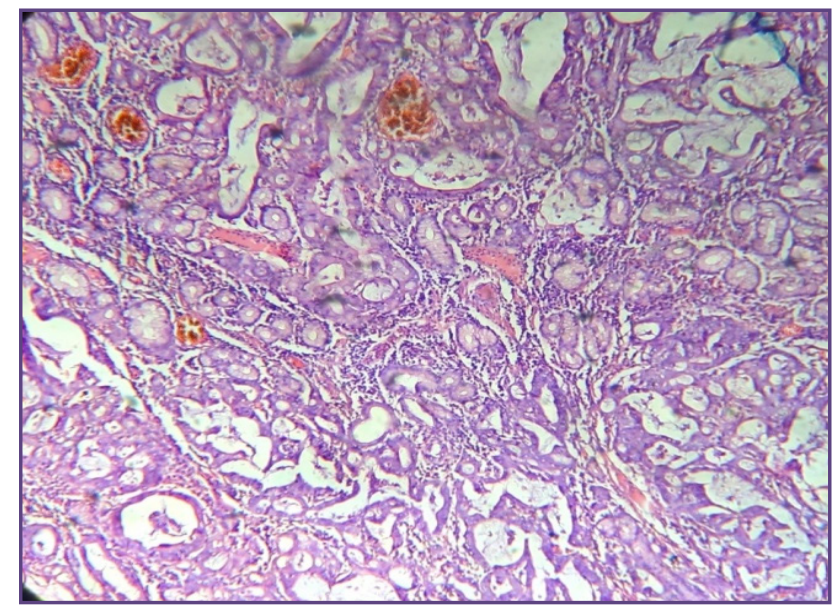

Fig. 2: Histopathology Showing Adenocarcinoma of Stomach.

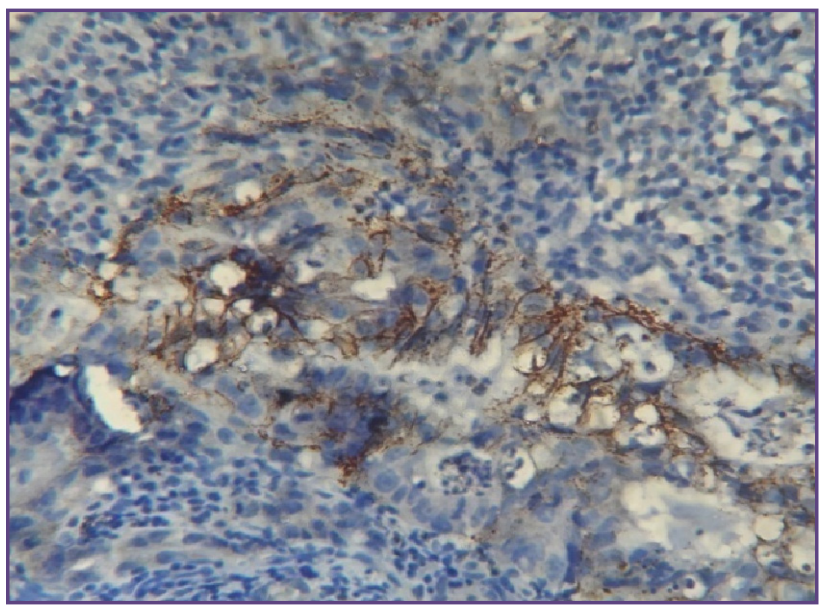

Fig. 4: IHC Showing Moderate Basolateral Staining In > $10 \%$ of Cells (Score 2+)

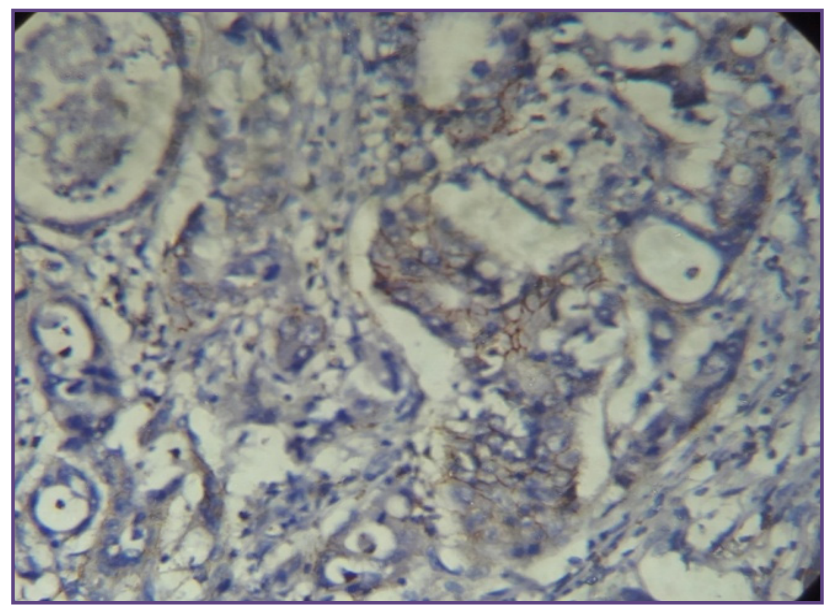

Fig.5 IHC Showing Faint Membranous Staining (Score 1+) 
In the present study, HER2/neu overexpression was found to be significantly associated with types of Gastric adenocarcinoma $(p=0.003)$ with highest expression in intestinal type of gastric carcinoma (56\%), followed by the diffuse type (7.1\%). The present study is in accordance with the finding of study conducted by Rajagopal I. et al. ${ }^{15}$ (2015), Gordon M.A. et al. ${ }^{16}$ (2013), Tewari M.et al. ${ }^{17}$ (2013), Yan S.Y.et al. ${ }^{18}$ (2011), Barros-Silva J. D.et al. ${ }^{19}$ (2009), Raziee H.R. et al. ${ }^{20}$ (2007), and Tanner M. et al. ${ }^{21}$ (2005). (Table:3) Although Movagharnejad K. et al. ${ }^{22}$ (2013) and Gomez-Martin C. et al. ${ }^{23}$ (2012), found majority of cases with HER2 expresion in intestinal type, no statistically significant association was found.

The present study also revealed a significant association between HER2/neu status and degree of differentiation of gastric carcinoma $(p=0.018)$. HER $2 /$ neu positivity rate was found highest among cases with moderately differentiated gastric carcinoma $(75 \%)$ followed by well differentiated gastric carcinoma (41.7) and poorly differentiated gastric carcinoma (19\%). The present study is in accordance with the findings of study conducted by Rajagopal I. et al. ${ }^{15}$ (2015) and Shan L. et al. ${ }^{24}$ (2013).(Table:4) Although Raziee H.R. et al. ${ }^{20}$ (2007) found association between HER2 status and degree of differentiation, majority of their cases were of well differentiated. Yan SY et al. ${ }^{18}$ (2011) found no association between HER2 status and degree of differentiation.

Role of HER2/neu expression in gastric carcinoma has been studied widely by different authors across the globe. HER2/neu protein overexpression in gastric carcinoma was found to be a poor prognostic indicator. Identification of biologically aggressive tumour by HER2 overexpression in gastric carcinomas is of prognostic significance, as in addition to traditional chemotherapy, Herceptin/ Trastuzumab will help increase survival rates of patients.

Trastuzumab was recently approved in many countries as a treatment modality for metastatic adenocarcinomas of the stomach and gastroesophageal junction. Inorder to ascertain whether trastuzumab therapy might be beneficial to a particular patient both HER2 scores and clinical correlation is a necessity.

\section{Conclusion}

In conclusion, the present study showed HER-2/neu overexpression was significantly associated with intestinal type and moderately differentiated type of gastric carcinoma. No significant association was found between HER2/ neu status with the other clinicopathological parameters. Hence, HER2/neu status can be considered as an important prognostic factor in gastric carcinoma.
In our study major limitation was the non-availability of FISH analysis for HER2/neu expression with 2+ positive cases which needs evaluation for better correlation. Further studies should be carried out with greater number of cases and longer duration of follow up of the patients, to highlight more on the significance of HER2/neu expression with prognosis of the patients.

\section{Acknowledgements}

We would like to acknowledge the Department of Surgery, $\mathrm{AMCH}$ and the Department of Medicine, $\mathrm{AMCH}$, for providing us excision biopsy and endoscopic biopsy samples to carryout our work. The authors are grateful to the technical staff for their help and support.

\section{Reference:}

1. Kamangar F, Dores GM, Anderson WF: Patterns of cancer incidence, mortality, and prevalence across five continents: defining priorities to reduce cancer disparities in different geographic regions of the world. J Clin Oncol. 2006, 24 (14): 2137-2150.

2. Lauwers GY, Carneiro F, Graham DY, Curado MP, Franceschi S, Montgomery E et al. Gastric carcinoma. Tumours of the stomach. WHO classification of Tumours of the Digestive System. 4th ed. Bosman F CFHRTN, editor: IARC Lyon; 2010.

3. Singh K, Ghoshal UC. Causal role of Helicobacter pylori infection in gastriccancer: An Asian enigma. World J Gastroenterol. 2006 Mar 7; 12(9): p. 1346-1351.

4. Dixit PR et al. in Epidemiological review of gastric cancer in India. Indian Journal of Medical \& Paediatric Oncology. 2011 Jan-Mar; 32(1): p. 3-11.

5. Rosai J. Gastrointestinal tract-Stomach. Rosai and Ackerman's Surgical Pathology. Vol-1, 10th ed. Missouri: MOSBY; 2011.

6. Rosai J. Breast. Rosai and Ackerman's Surgical Pathology. Vol-2,10th ed. Missouri: MOSBY; 2011.

7. Yu D, Hung MC. Overexpression of ErbB2 in cancer and ErbB2-targeting strategies. Oncogene. 2000; 19: p. 61156121.

8. Hogdall EV, Christensen L, Kjaer SK, Blaakaer J, Bock JE, Glud E et al. Distribution of HER-2 overexpression in ovarian carcinoma tissue and its prognostic value in patients with ovarian carcinoma: from the Danish MALOVA Ovarian cancer study. cancer. 2003; 98: p. 66-73.

9. Wang L, Habuchi T, Takahashi T, Kamoto T, Zuo T, Mitsumori K, et al. No association between HER-2 gene polymorphism at codon 655 and a risk of bladder cancer. Int J Cancer. 2002; 97: p. 787-790.

10. Ruschoff J, Dietel M, Baretton G, Arbogast S, Walch A, Monges G, et al. HER2 diagnostics in gastric cancerguideline validation and development of standardized immunohistochemical testing. Virchows Arch. 2010; 457: p. 299-307. 
11. Hofmann M, Stoss O, Shi D, Büttner R, van de Vijver M, Kim W,et al. Assessment of a HER2 scoring system for gastric cancer: results from a validation study. Histopathology. 2008; 52: p. 797-805.

12. Gürel S, Dolar E, Yerci O, Samli B, Oztürk H, Nak SG, et al. The relationship between c-erbB-2 oncogene expression and clinicopathological factors in gastric cancer. J Int Med Res. 1999; 27: p. 74-78.

13. Smith I, Procter M, Gelber RD et al. 2-year follow-up of trastuzumab after adjuvant chemotherapy in HER2-positive breast cancer: a randomised controlled trial. Lancet. 2007; 369(9555): p. 29-36.

14. Van Cutsem et al. Efficacy results from the ToGA trial: A phase III study of trastruzumab added to standard chemotherapy (CT) in first-line human epidermal growth factor receptor 2 (HER2)-positive advanced gastric cancer (GC). ASCO Abstract LBA. 2010.

15. Rajagopal I, Niveditha SR, Sahadev R, Nagappa PK and Rajendra SG. HER 2 Expression in Gastric and Gastroesophageal Junction (GEJ) Adenocarcinomas. J Clin Diagn Res. 2015 March; 9(3): p. 6-10.

16. Gordon MA, Gundacker HM, Benedetti J, Macdonald JS, Baranda JC, Levin WJ e al. Assessment of HER2 gene amplification in adenocarcinomas of the stomach or gastroesophageal junction in the INT-0116/SWOG9008 clinical trial. Press Ann Oncol. 2013 July; 24(7): p. 1754 1761 .

17. Tewari M, Kumar A, Mishra RR, KumarM and Shukla HS. HER2 Expression in Gastric and Gastroesophageal Cancer: Report from a Tertiary Care Hospital in North India. Indian J Surg. 2013.
18. Yan SY, Hu Y, Fan JG, Tao GQ, Lu YM, Cai X et al. Clinicopathologic significance of HER-2/neu protein expression and gene amplification in gastric carcinoma. World J Gastroenterol. 2011 March; 17(11): p. 1501-150.

19. Barros-Silva JD, Leitao D, Afonso L, Vieira J, Dinis-Ribeiro M, Fragoso M et al. Association of ERBB2 gene status with histopathological parameters and disease-specific survival in gastric carcinoma patients. British Journal of Cancer. 2009; 100: p. 487-493.

20. Raziee HR, Kermani TA, Ghaffarzadegan K, Shakeri T and Ghavamnasiri MR. HER-2/neu expression in resectable gastric cancer and its relationship with histolopathologic subtype , grade and stage. Iranian Journal of Basic Medical Sciences. 2007; 10(2): p. 139-145.

21. Tanner et al. Amplification of HER2 in gastric carcinoma: association with topoisomerase II alpha gene amplification, intestinal type, poor prognosis and sensitivity to trastuzumab.. Ann Oncol. 2005; 16: p. 2273-278.

22. Movagharnejad K, Sharbatdaran M, Sheffaee S, Kashifard M,and Sedagha S. HER-2/neu Marker Examination using Immunohistochemical Method in Patients Suffering from Gastric Adenocarcinoma. Int J Mol Cell Med. 2013 Autumn; 2(4): p. 199-203.

23. Gomez-Martin C, Garralda E, Echarri MJ, Ballesteros A, ArcedianoA, JRodríguez-Peralto JL et al. HER2/neu testing for anti-HER2-based therapies in patients with unresectable and/or metastatic gastric cancer. J Clin Pathol. 2012 August; 65(8): p. 751-757.

24. Shan L, Ying J and Lu N. HER2 expression and relevant clinicopathological features in gastric and gastroesophageal junction adenocarcinoma in a Chinese population. Diagnostic Pathology. 2013; 8: p. 76.

*Corresponding author:

Dr. Ashim Manta, Basic Science Building, Department of Pathology, Assam Medical College \& Hospital, Dibrugarh- 786002 Assam, India Phone: +918721091480

Email: ashims32@gmail.com

Financial or other Competing Interests: None. 